\title{
Perancangan Sistem Multi Computer Numerical Control (CNC) Untuk Plotter Dan Laser Engraving
}

\author{
Diki Muhamad Sobirin ${ }^{*}$, Jana Utama ${ }^{2}$ \\ 1,2)Program Studi Teknik Elektro, Fakultas Teknik dan Ilmu Komputer, Universitas Komputer Indonesia \\ Jl. Dipati Ukur No. 112 - 116, Bandung, Indonesia 40132 \\ *email:dikimuhamads@email.unikom.ac.id
}

(Naskah masuk: 07 Januari 2020; diterima untuk diterbitkan: 19 Februari 2020)

\begin{abstract}
ABSTRAK -Tujuan dari penelitian ini adalah membuat CNC yang memiliki dua fungsi dalam satu sistem serta dioperasikan dalam satu interface. Dengan memanfaatkan USB serial untuk komunikasi antara komputer dan mikrokontroler. Program untuk mengoperasikan CNC dirancang dengan menggunakan perangkat lunak LabVIEW, program akan mengkonversi gambar menjadi G-Code dan mengirim G-Code ke dalam sistem CNC untuk melakukan proses plotter atau laser engraving. CNC Plotter dapat membuat sebuah pola gambar pada kertas dengan bolpoin secara otomatis. Sementara itu, CNC Laser Engraving dapat membuat sebuah gravir pada kayu dengan memanfaatkan panas laser berdaya $500 \mathrm{mw}$, panas laser akan mengikis permukaan kayu secara otomatis. Dalam merancang multi CNC dua buah motor stepper digunakan sebagai akuator penggerak sumbu, dan motor servo sebagai penggerak bolpoin. Berdasarkan hasil pengujian, program pada LabVIEW dapat mengoperasikan sistem multi CNC dalam satu interface. CNC laser engraving dapat melakukan proses grafir pada kayu, serta dapat mengatur ketebalan grafir sesuai dengan kebutuhan. Selain itu, CNC Plotter dapat mencetak sebuah gambar bidang berbentuk kotak dengan ukuran terkecil $2 \mathrm{~mm} \times 2 \mathrm{~mm}$, dan lingkaran dengan diameter terkecil $2 \mathrm{~mm}$ dengan tingkat keberhasilan 100\%. Maksimal dimensi gambar yang dapat dikerjakan Multi CNC ini $300 \mathrm{~mm} \times 300 \mathrm{~mm}$.
\end{abstract}

Kata Kunci - Multi CNC, LabVIEW, Mikrokontroler. Laser, Plotter.

\section{Design Of Multi Computer Numerical Control (CNC) Systems For Plotter And Laser Engraving}

\begin{abstract}
The purpose of this research is to make CNC which has two functions in a system. By utilizing a USB serial for communication between a computer and a microcontroller. To operate CNC, the program is designed using LabVIEW software, the program will convert images into G-Code and send G-Code into the CNC system to do the plotter or laser engraving process. CNC plotter can make an image pattern on paper with a ballpoint automatically. Meanwhile, CNC Laser Engraving can make a engraving on wood by utilizing a 500 mw laser heat, laser heat will erode the surface of the wood automatically. In designing multi CNC, two stepper motors are used as the axis actuator, and a servo motor is used as the activator of the ballpoint. Based on the test results, the program at LabVIEW can convert images into G-Code lasers, then the program send G-Codes into a CNC system, as the result CNC can process laser engraving on wood as well as set the thickness of the engraving as the need. The ideal feedrate is 50-500 mm / minute and the maximum is $2000 \mathrm{~mm} /$ minute. On the other hand, CNC Plotter is able to print a square shape image with the smallest size of $2 \mathrm{~mm} \times 2 \mathrm{~mm}$, and the circle with the smallest diameter of $2 \mathrm{~mm}$ with 100\% success rate. The maximum dimensions of images that can be done by Multi CNC are $300 \mathrm{~mm} x 300 \mathrm{~mm}$.
\end{abstract}

Keywords - Multi CNC, LabVIEW, Microcontroller. Laser, Plotter.

\section{Pendahuluan}

Ilmu pengetahuan dan teknologi saat ini perkembang pesat, di bidang elektronika maupun mekanika. Dunia industri dahulu sistem kerjanya masih tenaga manual, peran manusia pada saat itu sangat dominan, namun sistem saat ini berkembang pesat beralih menjadi otomatis menggunakan robot 
[1]. Oleh karena masyarakat di era ini ingin hal yang cepat dan praktis dalam segala hal, salah satunya menghasilkan sebuah produk dengan kualitas yang bagus. Maka dibutuhkanlah peralatan pendukung untuk industri modern, diantaranya adalah mesinmesin Computer Numerical Control (CNC) [2]. Teknologi permesinan dan sistem cerdas modern mahal, membutuhkan penanganan yang mudah dan mesin yang terintegrasi dengan beragam perangkat untuk melakukan beberapa tugas permesinan. Mesin CNC dapat digunakan oleh produsen untuk melakukan beberapa tugas pemesinan, karena lebih efektif dalam menangani keakurasian [3].

CNC dapat dikelompokkan menjadi dua jenis, yaitu mesin rotari dan mesin giling. Rotari mesin pada dasarnya adalah perangkat yang memutar bagian material pada kecepatan sangat tinggi, pemintal bergerak maju, mundur dan keluar sampai bentuk yang disukai selesai. Penggilingan mesin adalah mesin yang memiliki spindle yang mirip dengan router, dengan sebuah laser yang dapat memotong berbagai arah dan bergerak dalam tiga arah di sepanjang X, Y, dan sumbu Z [4]. Sistem laser engraving pada $\mathrm{CNC}$ sangat diperlukan, karena dapat mengukir, menggores dan memotong bahan desain sesuai keinginan dengan kualitas yang baik [5]. Seperti diketahui laser seperti pensil, pola yang berbeda dapat diukir oleh pemrograman modul kontrol untuk melintasi jalur tertentu dari sinar laser [6].

Pada saat ini sistem CNC hanya memiliki satu fungsi dalam satu sistem [7]. Adapun untuk mengoperasikan $\mathrm{CNC}$ saat ini harus lebih dari satu software seperti halnya CNC plotter. Gambar harus terlebih dahulu dikonversi menjadi G-Code dengan software inkscape dan G-Code dikirim menggunakan Universal G-Code Sender. Sedangkan pada saat ini belum adanya software dalam satu interface, untuk mengendalikan dua sistem CNC [8]. G-Code adalah fungsi untuk memberi tahu mesin untuk berpindah ke berbagai titik dengan kecepatan yang diinginkan [9]. Berdasarkan latar belakang tersebut dibuatlah, sistem multi CNC yang memiliki dua fungsi dalam satu sistem. Sistem multi CNC dapat membuat grafir laser pada kayu, dan dapat membuat sebuah pola gambar pada kertas dengan menggunakan bolpoin secara otomatis. Sistem multi CNC dioprasikan dengan satu software berbasis LabVIEW. Program dapat mengkonversi gambar menjadi G-Code dan mengirim G-Code ke dalam sistem multi CNC hanya dalam satu interface. Sehingga lebih memudahkan dalam mengoperasikan sistem multi CNC tersebut. Dengan Sistem CNC yang memiliki dua fungsi dalam satu sistem CNC berbiaya rendah melayani banyak tujuan [10]. Pengetahuan yang komprehensif tentang kualitas dan biaya operasi akan membantu pengguna untuk menilai metode mana yang lebih tepat untuk setiap jenis aplikasi [11].

\section{METODE DAN BAHAN}

\subsection{Metode Perancangan Sistem Multi CNC}

Perancangan Sistem multi CNC untuk Plotter dan Laser Engraving membutuhkan komponen pendukung. Seperti mikrokontroler Arduino, CNC Shiled, driver motor, untuk aktuator penggerak membutuhkan dua buah motor stepper Nema 17, dan motor servo, kabel USB untuk mentransfer data dari Komputer, dan memasok arus ke Arduino Board, dan memasok arus [12]

\section{A. Blok Diagram}

Dalam perancangan dan pembuatan alat ada hal yang harus diperhatikan, diantaranya blok diagram yang harus dipahami. Agar memudahkan dalam proses perancangan, blok diagram dapat dilihat pada Gambar 1.

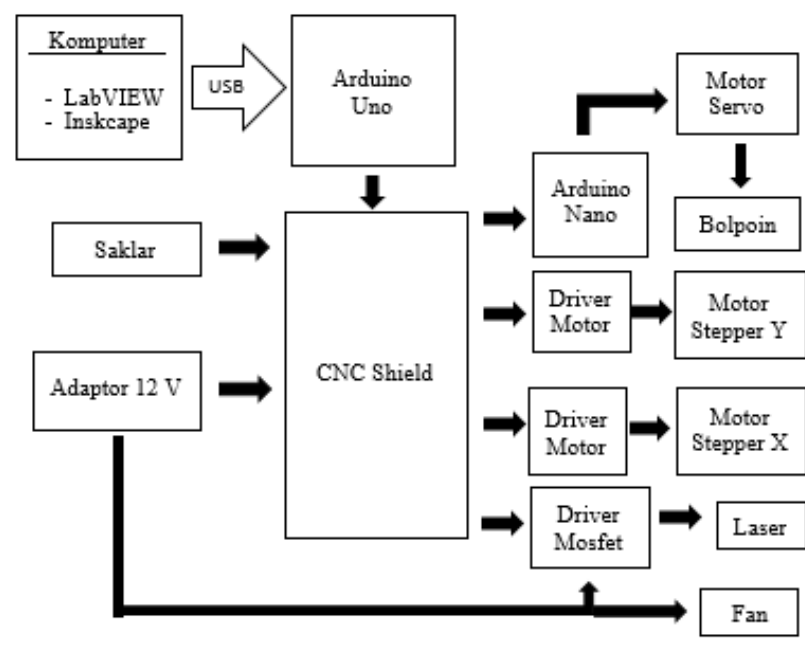

Gambar 1. Blok diagram

Input yang digunakan adalah aplikasi pada komputer. Aplikasi yang digunakan diantaranya. Inkscape digunakan untuk membuat pola gambar vektor, lalu gambar vektor dimasukan ke dalam aplikasi. Gambar tersebut harus konversi menjadi line art vektor untuk sistem CNC Plotter, lalu gambar tersebut disimpan ke dalam format G-Code.

LabVIEW digunakan untuk mengkonversi gambar menjadi G-Code dan juga mengirim data GCode ke mikrokontroler. Dengan cara memasukan gambar yang akan konversi menjadi G-Code, jalankan LabVIEW setelah itu klik tombol generate. Maka GCode dari gambar dapat di simpan ataupun dikirim ke mesin CNC. Untuk mengirim data G-Code hubungkan USB serial pada CNC ke komputer, dan pilih port sesuai dengan mikrokontroler CNC. Jalankan LabVIEW dan klik run maka CNC akan berjalan sesuai dengan pilihan apakah akan 
melakukan Plotter dengan bolpoin atau Laser Engraving, untuk memilih cukup mengatur saklar yang terhubung ke CNC shiled pin 11 atau pin Z+.

\section{B. Perancangan Mekanik}

Perancangan sistem multi CNC untuk plotter dan laser engraving, membutuhkan mekanik yang bisa memiliki 2 fungsi. Berikut adalah tahap perancangan.

\section{a Membuat Desain}

Sistem Multi Computer Numerical Control (CNC) untuk Plotter dan laser Engraving dalam penelitian ini. Desain menggunakan perangkat lunak Blender, dimana rel axis $\mathrm{Y}$ menggunakan linier guide, rel axis $\mathrm{X}$ menggunakan 3 buah roda. Sedangkan jenis servo yang digunakan SG90 untuk menaik turunkan bolpoin, dan laser yang digunakan laser $500 \mathrm{mw}$. Bahan yang digunakan alumunium profile, dan untuk kaki-kaki menggunakan akrilik. Desain dapat dilihat pada Gambar 2.

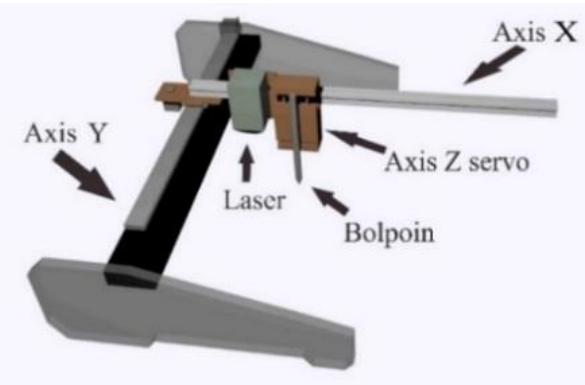

Gambar 2. Desain Multi CNC

\section{b Membuat Axis Y}

Didalam axis $Y$, terdapat, motor stepper, akrilik sebagai dudukan stepper dan kaki dari CNC. Alumunium profil sebagai dudukan linier guide rail (sebagai rel) dengan panjang $30 \mathrm{~cm}$. Axis Y dapat dilihat pada Gambar 3.

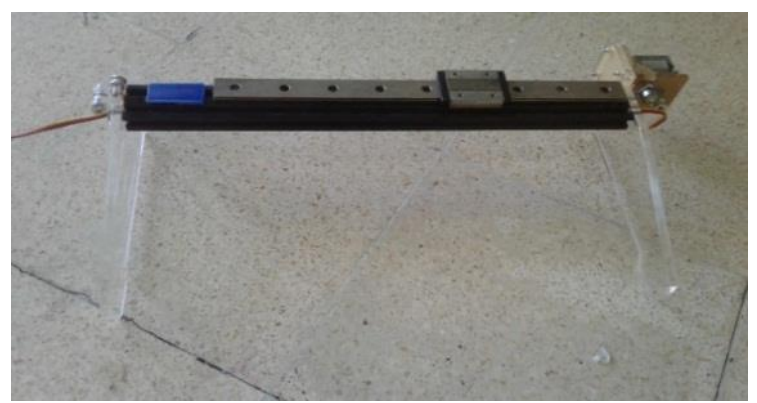

Gambar 3. Mekanik Axis Y

\section{c Membuat Axis X}

Didalam axis $\mathrm{X}$, terdapat motor stepper, dengan dudukan akrilik, serta alumunium profil dengan panjang $30 \mathrm{~cm}$ dan roda yang digunakan untuk rel CNC. Mekanik axis X dapat dilihat pada Gambar 4.

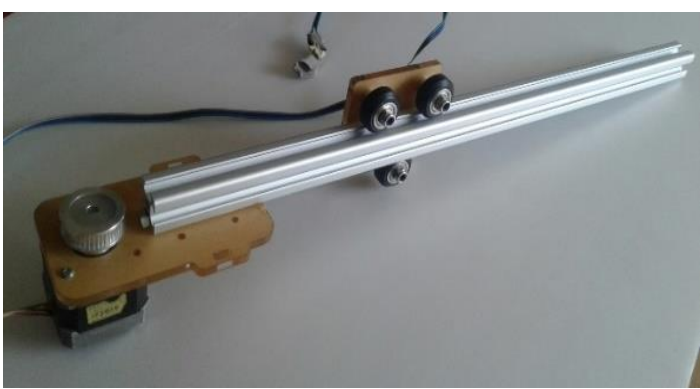

Gambar 4. Mekanik Axis X

d Membuat axis $\mathrm{Z}$ motor servo

Membuat mekanik axis $Z$ dan pen holder, untuk menaik turunkan bolpoin, mekanik axis $\mathrm{Z}$ dapat dilihat pada Gambar 5.

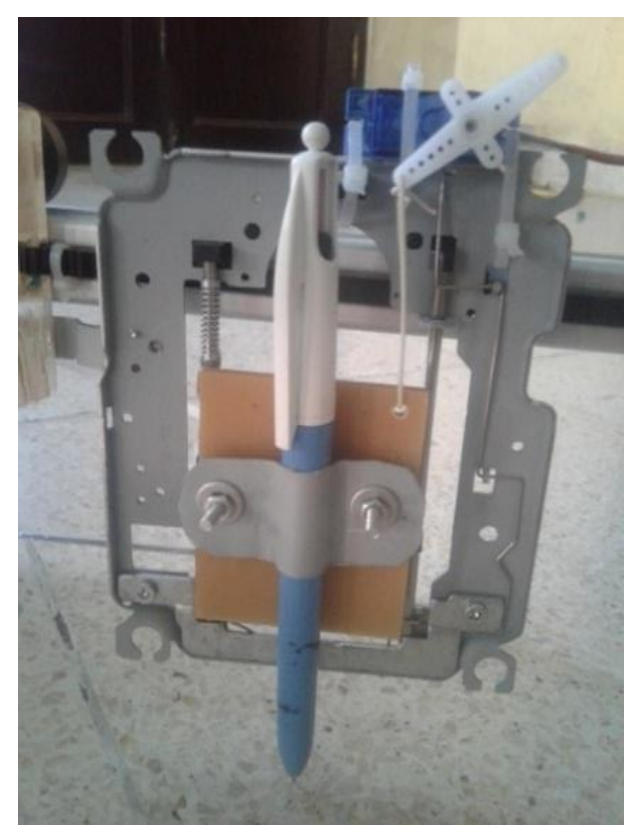

Gambar 5. Mekanik Axis Z Servo

e Menggabungkan Axis X, Axis Y, dan Axis Z.

Mengabungkan axis $Y$ pada linier guide rail yang terpasang pada axis $\mathrm{X}$, dan memasang belt pada puly, dan memasangkan laser 500mw pada mekanik axis $Y$.

\section{Perancangan Komponen Elektronika}

Dalam perancangan alat ini dibutuhkan 2 buah motor stepper sebagai penggerak, Axis X dan, Axis $Y$, yang mana motor stepper yang digunakan adalah motor stepper jenis bipolar. Motor stepper tersebut dihubungkan ke CNC shield yang sudah terpasang pada arduino uno, dan sudah terpasang motor driver. Arduino nano digunakan untuk mekonversi sinyal kontrol laser menjadi sinyal pwm untuk menggerakan motor servo. Adapun daya laser yang digunakan $500 \mathrm{mw}$, modul IRF520 digunakan sebagai driver laser. Sedangkan Fan digunakan 
untuk menjaga suhu komponen di dalam box komponen. Untuk memilih mode laser engraving atau plotter menggunakan saklar yang terhubung langsung dengan CNC shield pin D11 pada arduino uno. Skematik multi CNC dapat dilihat pada Gambar 6.

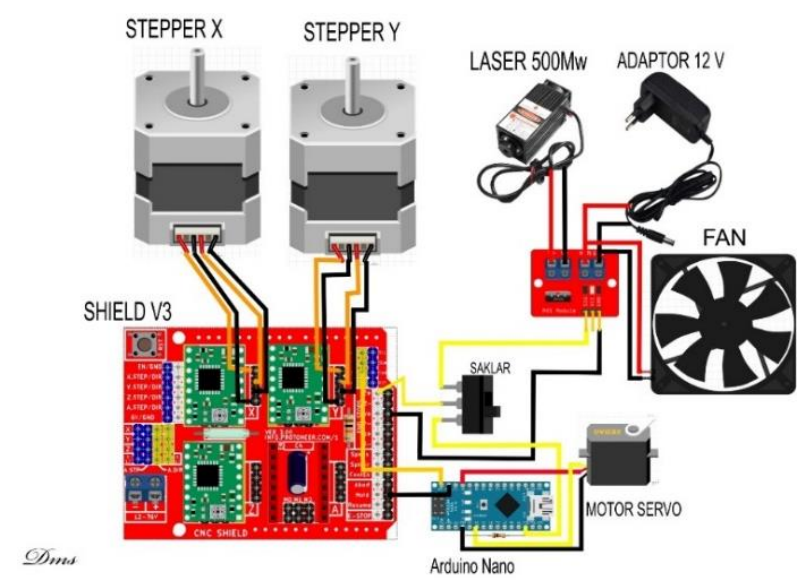

Gambar 6. Skema Multi CNC

\section{Hasil Perancangan CNC}

Setelah melakukan semua tahapan perancangan mekanik dan perancangan Elektronika. Berikut adalah hasil implementasi CNC Plotter yang mana sudah terdapat 2 Axis $Y$, Axis $X$, dan Axis $Z$ servo untuk CNC Plotter. Multi CNC ini maksimal dapat mencetak gambar dengan ukuran $300 \mathrm{~mm} \times 300 \mathrm{~mm}$. Multu CNC Dapat dilihat pada Gambar 7.

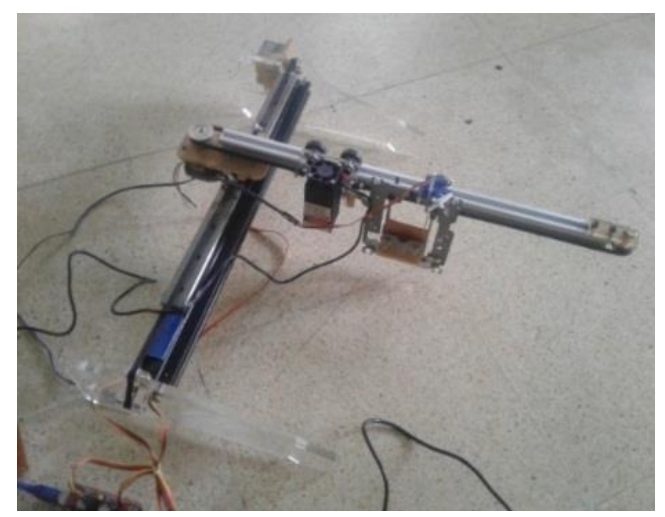

Gambar 7. Implementasi Multi CNC

\subsection{Perancangan Perangkat Lunak}

Dalam melakukan perancangan perangkat lunak ada hal yang harus diperhatikan, diantaranya. Flowchart yang harus dipahami agar memudahkan dalam proses perancangan.

\section{A. Flowchart Perangkat Lunak}

Perangkat lunak dibuat menggunakan program LabVIEW. Perancangan perangkat lunak meliputi pembuatan program konversi dari gambar menjadi kode gerakan (G-Code). Gambar RGB dikonversi menjadi gambar grayscale. Citra grayscale atau citra skala keabuan mempunyai kemungkinan warna antara hitam (minimal) dan putih (maksimal). Citra biner adalah citra yang setiap titik atau pikselnya bernilai 0 atau 1 dengan representasi warna hitam $=$ 0 , dan warna putih $=1$ [13]. Setelah itu pixel hitam atau pixel 0 dikonversi menjadi koordinat array, dan koordinat array tersebut dikonversi menjadi G-Code. Setelah itu menggabungkan program konversi dengan program Universal G-Code Sender. Flowchart program G-Code converter dan G-Code Sender dapat dilihat pada Gambar 8 .

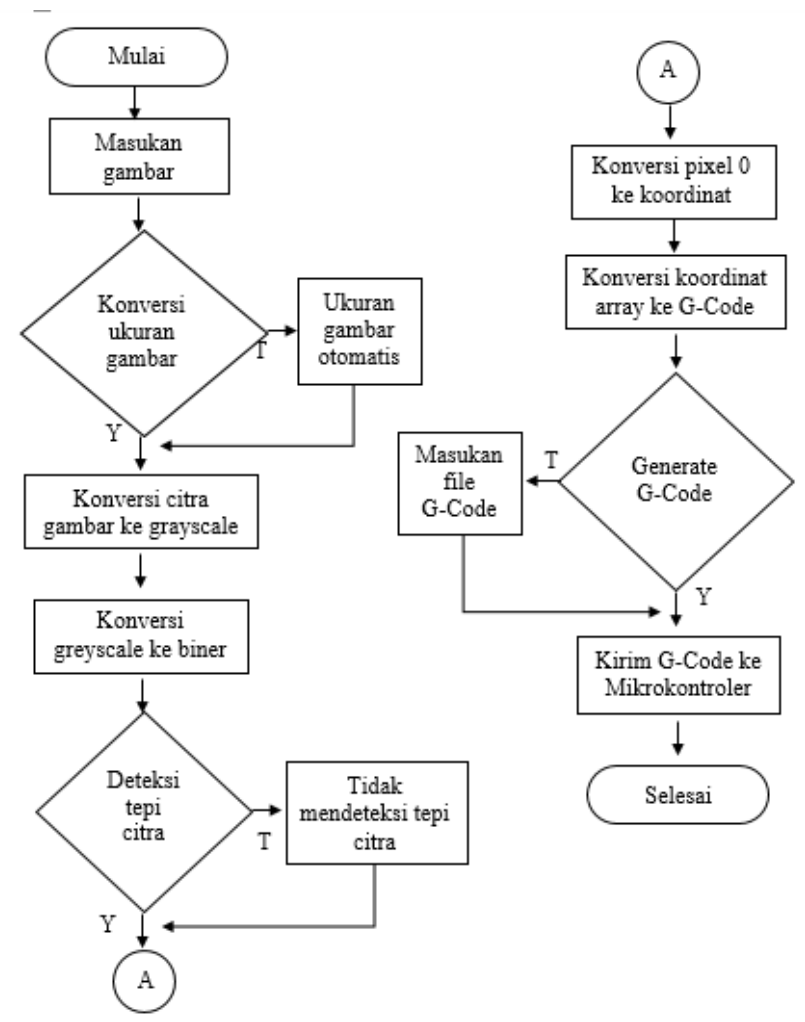

Gambar 8. Flowchart G-Code Converter dan GCode Sender

\section{B. Hasil Perancangan Perangkat Lunak}

Setelah melakukan semua tahap perancangan perangkat lunak, berikut adalah program hasil perancangan perangkat lunak pada LabVIEW yang sudah dapat digunakan untuk mengoperasikan multi CNC. Dapat dilihat pada Gambar 9.

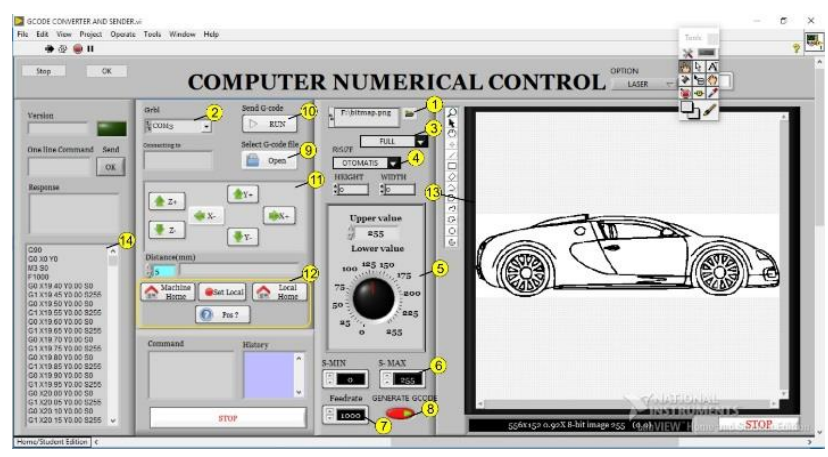

Gambar 9. Hasil perancangan perangkat lunak pada LabVIEW 
Fungsi tool yang ada pada tampilan LabVIEW Gambar 9.

1. Image file untuk memasukan gambar yang akan digrafir laser.

2. Untuk memilih port mikrokontroler multi CNC.

3. Untuk memilih mode gambar apakah gambar yang akan digrafir dengan mode deteksi tepi, atau gambar asli.

4. Untuk memilih mode gambar, apakah gambar yang akan digrafir konversi ukuran nya, atau gambar original yang akan digrafir.

5. Untuk mengatur ambang (treshold) gambar.

6. Untuk mengatur power laser.

7. Untuk mengatur feedrate (kecepatan pemakan).

8. Generate G-Code untuk menghasilkan G-Code dari gambar yang sudah diproses.

9. Untuk memasukan G-Code plotter yang sudah dibuat di inkscape.

10. Untuk mengirim G-Code ke mikrokontroler CNC.

11. Untuk menggerakan Axis X dan Axis Y secara manual.

12. Untuk mengatur titik nol CNC.

13. Untuk menampilkan gambar yang sudah dimasukan.

14. Untuk menampilkan hasil G-Code yang sudah digenerate dari gambar.

\section{HASIl DAN PEMbahasAN}

\subsection{Pengujian dan Analisis}

Pengujian dan analisis data adalah langkah untuk mengetahui sistem yang sudah dibuat bekerja sesuai dengan yang direncanakan. Sebelum melakukan pengujian maka dibutuhkan penggaris untuk mengukur keakurasian hasil percobaan, dan kertas untuk media Plotter. Dengan melakukan beberapa percobaan maka dapat melakukan analisis data.

\section{A. Pengujian Plotter dengan vektor kotak}

Pengujian dilakukan dengan membuat vektor berbentuk kotak, Pengujian vektor kotak dilakukan agar dapat mengetahui ukuran gambar terkecil yang dapat di cetak dengan CNC Plotter dan dapat mengetahui tingkat akurasi CNC Plotter. Proses pengujian dapat dilihat pada Gambar 10.

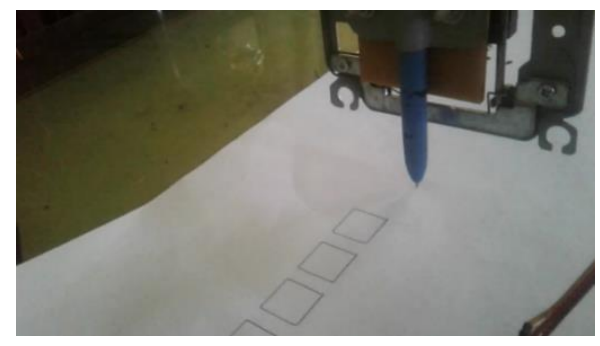

Gambar 10. Proses pengujian vektor kotak.
Pengujian dilakukan dengan 5 percobaan, dengan ukuran bidang berbentuk kotak yang berbeda-beda. Hasil pengujian dapat dilihat pada Tabel 1.

Tabel 1. Hasil pengujian dengan vektor kotak

\begin{tabular}{|c|c|c|c|}
\hline No. & Ukuran & Hasil Pengujian & Keterangan \\
\hline 1 & $\begin{array}{c}2 \mathrm{~mm} x \\
2 \mathrm{~mm}\end{array}$ & & $\begin{array}{l}10 \text { gambar vektor } \\
\text { kotak berhasil di } \\
\text { cetak sesuai, } \\
\text { dengan ukuran } 2 \\
\mathrm{~mm} \times 2 \mathrm{~mm}\end{array}$ \\
\hline 2 & $\begin{array}{c}3 \mathrm{~mm} x \\
3 \mathrm{~mm}\end{array}$ & 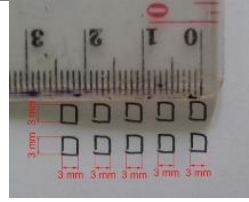 & $\begin{array}{l}10 \text { gambar vektor } \\
\text { kotak berhasil di } \\
\text { cetak sesuai, } \\
\text { dengan ukuran } 3 \\
\text { mm x } 3 \mathrm{~mm}\end{array}$ \\
\hline 3 & $\begin{array}{c}5 \mathrm{~mm} x \\
5 \mathrm{~mm}\end{array}$ & 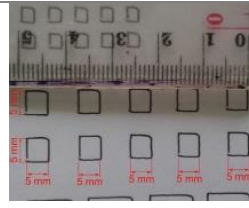 & $\begin{array}{l}10 \text { gambar vektor } \\
\text { kotak berhasil di } \\
\text { cetak sesuai, } \\
\text { dengan ukuran } 5 \\
\mathrm{~mm} \times 5 \mathrm{~mm}\end{array}$ \\
\hline 4 & $\begin{array}{c}10 \mathrm{~mm} \\
\times 10 \\
\mathrm{~mm}\end{array}$ & & $\begin{array}{l}10 \text { gambar vektor } \\
\text { kotak berhasil di } \\
\text { cetak sesuai, } \\
\text { dengan ukuran } 10 \\
\mathrm{~mm} \times 10 \mathrm{~mm}\end{array}$ \\
\hline 5 & $\begin{array}{c}15 \mathrm{~mm} \\
\times 15 \\
\mathrm{~mm}\end{array}$ & $=4.15 \mathrm{~mm}$ & $\begin{array}{l}10 \text { gambar vektor } \\
\text { kotak berhasil di } \\
\text { cetak sesuai, } \\
\text { dengan ukuran } 15 \\
\mathrm{~mm} \times 15 \mathrm{~mm}\end{array}$ \\
\hline
\end{tabular}

Dari hasil pengujian pada Tabel 1 dengan pengujian vektor kotak. Gambar vektor kotak dengan ukuran terkecil, berukuran $2 \mathrm{~mm} \times 2 \mathrm{~mm}$ dapat di cetak oleh CNC plotter pada bidang kertas sesuai dengan ukurannya. Pengujian dilakukan dengan 5 pengujian, ukuran gambar mulai dari $2 \mathrm{~mm}$ x $2 \mathrm{~mm}-15 \mathrm{~mm} \times 15 \mathrm{~mm}$ dan berhasil di cetak sesuai dengan ukuran. Berdasarkan hasil pengujian CNC plotter dapat mencetak sebuah bidang gambar berbentuk kotak berukuran kecil, hingga $2 \mathrm{~mm}$ dengan tingkat keberhasilan $100 \%$.

\section{B. Pengujian Plotter dengan vektor lingkaran}

Pengujian dilakukan dengan membuat vektor berbentuk lingkaran. Pengujian vektor lingkaran dilakukan agar dapat mengetahui ukuran gambar lingkaran terkecil yang dapat di cetak dengan $\mathrm{CNC}$ Plotter, dan dapat mengetahui tingkat akurasi CNC Plotter. Proses pengujian dapat dilihat pada Gambar 11. Hasil pengujian dapat dilihat pada Tabel 2. 
D M Sobirin \& J Utama

Komputika: Jurnal Sistem Komputer, Vol. 9, No. 1, April 2020

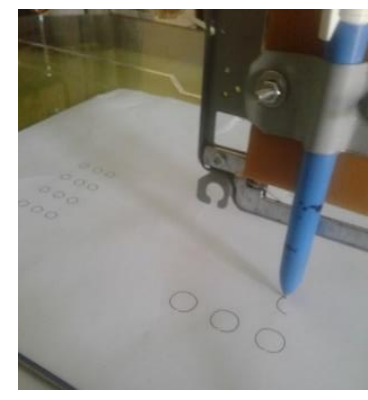

Gambar 11. Proses pengujian vektor lingkatan

Pengujian dilakukan dengan 5 percobaan, percobaan dilakukan dengan diameter lingkaran berbeda-beda. Hasil pengujian dapat dilihat pada Tabel 2.

Tabel 2. Hasil pengujian dengan vektor lingkaran

\begin{tabular}{|c|c|c|c|}
\hline No. & $\begin{array}{l}\text { Dia- } \\
\text { meter }\end{array}$ & $\begin{array}{c}\text { Hasil } \\
\text { Pengujian }\end{array}$ & Keterangan \\
\hline 1 & $2 \mathrm{~mm}$ & $\begin{array}{lll}0 & 0 & 0 \\
0 & 0 & 0\end{array}$ & $\begin{array}{c}10 \text { gambar vektor } \\
\text { lingkaran berhasil } \\
\text { di cetak sesuai, } \\
\text { dengan diameter } \\
2 \mathrm{~mm} \text {. }\end{array}$ \\
\hline 2 & $3 \mathrm{~mm}$ & $\begin{array}{ccc}0 & 0 & 0 \\
3 \mathrm{~mm} & 3 \mathrm{mim} & 3 \mathrm{~mm}\end{array}$ & $\begin{array}{l}10 \text { gambar vektor } \\
\text { lingkaran berhasil } \\
\text { di cetak sesuai, } \\
\text { dengan diameter } \\
3 \mathrm{~mm} \text {. }\end{array}$ \\
\hline 3 & $5 \mathrm{~mm}$ & $8 \quad 8$ & $\begin{array}{l}10 \text { gambar vektor } \\
\text { lingkaran berhasil } \\
\text { di cetak sesuai, } \\
\text { dengan diameter } \\
5 \mathrm{~mm} \text {. }\end{array}$ \\
\hline 4 & $10 \mathrm{~mm}$ & & $\begin{array}{l}10 \text { gambar vektor } \\
\text { lingkaran berhasil } \\
\text { di cetak sesuai, } \\
\text { dengan diameter } \\
10 \mathrm{~mm} .\end{array}$ \\
\hline 5 & $15 \mathrm{~mm}$ & & $\begin{array}{c}10 \text { gambar vektor } \\
\text { lingkaran berhasil } \\
\text { di cetak sesuai, } \\
\text { dengan diameter } \\
15 \mathrm{~mm} .\end{array}$ \\
\hline
\end{tabular}

Dari hasil pengujian pada Tabel 2 dengan pengujian vektor lingkaran. Gambar vektor lingkaran dengan ukuran terkecil, berdiameter $2 \mathrm{~mm}$ di cetak oleh CNC plotter pada bidang kertas sesuai dengan ukurannya. Pengujian dilakukan dengan 5 pengujian, diameter gambar mulai dari $2 \mathrm{~mm}-15$ $\mathrm{mm}$ dan berhasil di cetak sesuai dengan diameter. Berdasarkan hasil pengujian CNC plotter dapat mencetak sebuah bidang gambar berbentuk lingkaran berukuran kecil, hingga $2 \mathrm{~mm}$ dengan tingkat keberhasilan 100\%.

\section{Pengujian Laser Engraving}

Pengujian laser engraving dilakukan dengan media grafir kayu. Setiap percobaan dilakukan, dengan mengaturan kecepatan grafir, untuk menghasilkan grafir dengan ketebalan yang bervariasi dan mendapatkan ketebalan yang baik.. proses percobaan dapat dilihat pada Gambar 12.

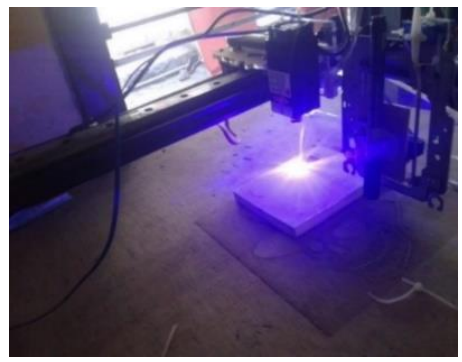

Gambar 12. Proses pengujian laser engraving

Percobaan dilakukan dengan menggunakan 10 variasi kecepatan pemakan. Hasil percobaan dapat dilihat pada Tabel 3.

Tabel 3. Tabel hasil pengujian laser engraving

\begin{tabular}{|c|c|c|c|c|}
\hline No. & Feedrate & Tegangan & Vektor & Hasil \\
\hline 1 & $50 \mathrm{~mm} /$ menit & 12 Volt & & \\
\hline 2 & $100 \mathrm{~mm} /$ menit & 12 Volt & & \\
\hline 3 & $150 \mathrm{~mm} /$ menit & 12 Volt & & \\
\hline 4 & $200 \mathrm{~mm} /$ menit & 12 Volt & & \\
\hline 5 & $250 \mathrm{~mm} /$ menit & 12 Volt & & \\
\hline 6 & $300 \mathrm{~mm} /$ menit & 12 Volt & & \\
\hline 7 & $350 \mathrm{~mm} /$ menit & 12 Volt & & \\
\hline 8 & $400 \mathrm{~mm} /$ menit & 12 Volt & & \\
\hline 9 & $450 \mathrm{~mm} /$ menit & 12 Volt & & \\
\hline 10 & $500 \mathrm{~mm} /$ menit & 12 Volt & & \\
\hline
\end{tabular}

Berdasarkan percobaan pada Tabel 3, Pengujian pertama dilakukan dengan feedrate grafir 50 
$\mathrm{mm} /$ menit dengan power laser $500 \mathrm{mw}$, hasil grafir menunjukan ketebalan grafir lebih hitam dan terkikis lebih dalam pada feedrate yang rendah, sedangkan pada percobaan dengan feedrate 100-500 mulai terlihat perbedaan ketebalan pengikisan dan warna, semakin rendah feedrate maka hasil grafir akan tebal dan terkikis lebih dalam, semakin besar feedrate maka proses pengikisan akan lebih rendah dan warna tidak terlalu hitam, tetapi semakin rendah feedrate maka proses grafir akan semakin lama, dan semakin besar feedrate maka proses grafir akan cepat, pada percobaan dengan feedrate $50 \mathrm{~mm} /$ menit, waktu grafir dengan vektor kotak $10 \mathrm{~mm} \times 10 \mathrm{~mm}$ adalah 7,33 detik, sedangkan feedrate $500 \mathrm{~mm} /$ menit dengan vektor yang berukuran sama, waktu proses grafir 2,16 detik. Pengaturan ketebalan tersebut dapat digunakan sesuai kebutuhan ketika akan membuat sebuah grafir dengan desain apapun sesuai dengan selera, apabila ingin warna yang lebih hitam pekat menggunakan feedrate lebih rendah, dan apabila ingin warna yang di hasilkan lebih cerah gunakan feedrate lebih tinggi. Pada penelitian sebelumnya menggunakan 4 variasi kecepatan pemakan, dan media grafir menggunakan akrilik, triplek dan kertas karton, dan kecepatan pemakan maksimal menggunakan 200 mm/menit [14]. Sedangkan pada penelitian ini menggunakan 10 variasi kecepatan pemakan. Adapun media grafir menggunakan kayu, dengan banyak nya variasi kecepatan pemakan membuat banyak pilihan ketebalan sesuai dengan keinginan, dan kecepatan pemakan pada penelitian ini maksimal bisa $2000 \mathrm{~mm} /$ menit sehingga dapat lebih cepat dibandingkan penelitian sebelumnya.

\subsection{Percobaan Plotter Dan Laser Engraving}

Percobaan dilakukan dengan membuat vektor mobil. Percobaan plotter dan laser engraving ini dilakukan untuk mengetahui bahwa multi CNC ini sudah dapat membuat sebuah pola gambar dengan bolpoin,, dan dapat melakukan proses grafir pada media kayu dengan menggunakan laser.

\section{A. Percobaan Plotter}

Percobaan plotter dilakukan dengan menggunakan gambar vektor mobil, dengan ukuran $157 \mathrm{~mm} \times 43 \mathrm{~mm}$ dan feedrate $1000 \mathrm{~mm} /$ menit. Hasil percobaan Plotter menunjukan bahwa Plotter dapat melakukan proses mencetak pola gambar dengan ukuran yang dicetak, sesuai dengan vektor yaitu 157 $\mathrm{mm} \times 43 \mathrm{~mm}$. Sedangkan untuk detail gambar yang dihasilkan pada objek vektor yang berukuran kecil seperti detail velk mobil tidak rapih, karena pada saat servo menggerakan bolpoin terlalu cepat. Sehingga menghasilkan getaran pada mekanik Axis Z, yang menyebabkan bolpoin bergetar dan hasilnya tidak rapih pada gambar detail vektor yang kecil, pada penelitian sebelumnya sumbu $\mathrm{Z}$ menggunakan motor stepper, dan ukuran gambar yang di cetak maksimal $40 \mathrm{~mm} \times 40 \mathrm{~mm}$ [15]. Percobaan Plotter dapat dilihat pada Gambar 13.

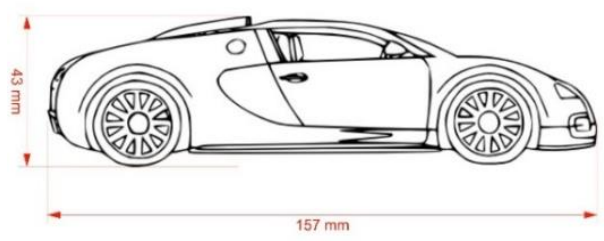

(a) Vektor untuk Plotter

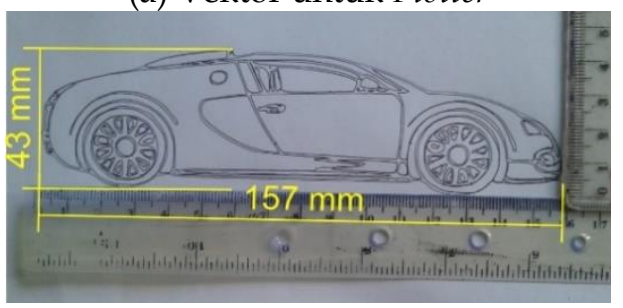

(b) Hasil Plotter

Gambar 13. Percobaan Plotter (a) Vektor (b) Hasil Plotter

\section{B. Percobaan Laser Engraving}

Percobaan laser engraving dilakukan dengan menggunakan gambar vektor mobil. Dengan ukuran $38 \mathrm{~mm} \times 10 \mathrm{~mm}$ dan kecepatan pemakan 1000 $\mathrm{mm} /$ menit. Hasil percobaan engraving menunjukan bahwa CNC dapat melakukan proses grafir pada kayu. Pola gambar vektor mobil sesuai dengan ukuran yaitu $38 \mathrm{~mm} \times 10 \mathrm{~mm}$, dengan daya laser yang digunakan $500 \mathrm{mw}$. Pada percobaan ini gambar yang dihasilkan baik dan garis tidak ada yang terputus, sedangkan pada penelitian sebelumnya kecepatan pemakan menggunakan $400 \mathrm{~mm} /$ menit dengan hasil garis yang terputus-putus [16]. Percobaan laser engraving dapat dilihat pada Gambar 14.

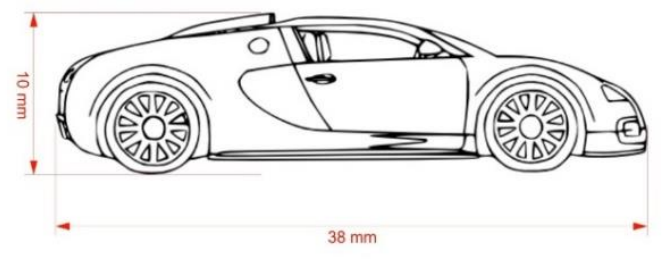

(a) Vektor untuk laser engraving

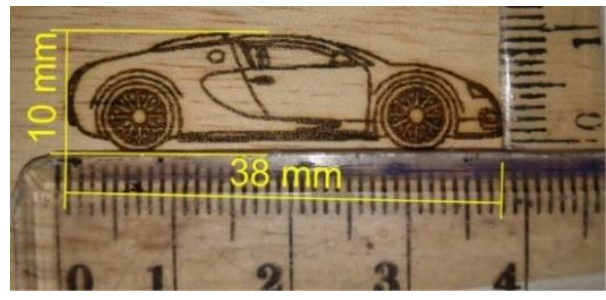

(b) Hasil laser engraving

Gambar 14. Percobaan laser engraving (a) Vektor untuk laser engraving (b) Hasil laser engraving 


\section{KESIMPULAN}

Berdasarkan hasil pengujian dalam penelitian ini, Program pada LabVIEW dapat mengkonversi gambar menjadi G-Code laser, dan program dapat mengirim G-Code ke dalam sistem $\mathrm{CNC}$, sehingga $\mathrm{CNC}$ dapat melakukan proses grafir laser pada kayu serta dapat mengatur ketebalan grafir sesuai dengan kebutuhan. Adapun kecepeatan pemakan ideal 50$500 \mathrm{~mm} /$ menit dan kecepatan pemakan maksimal 2000 mm / menit. Sementara itu, CNC Plotter dapat mencetak sebuah gambar bidang berbentuk kotak dengan ukuran terkecil $2 \mathrm{~mm} \times 2 \mathrm{~mm}$, dan lingkaran dengan diameter terkecil $2 \mathrm{~mm}$ dengan tingkat keberhasilan 100\%. Maksimal dimensi gambar yang dapat dikerjakan Multi CNC ini 300 mm x 300 mm.

\section{DAFTAR PUSTAKA}

[1] K. Wu, C. Krewet, and B. Kuhlenkötter, "Dynamic performance of industrial robot in corner path with CNC controller," Robot. Comput. Integr. Manuf., vol. 54, no. May, pp. 156161, 2018, doi: 10.1016/j.rcim.2017.11.008.

[2] G. M. Martinov, A. I. Obuhov, L. I. Martinova, and A. S. Grigoriev, "An approach to building specialized CNC systems for non-traditional processes," Procedia CIRP, vol. 14, pp. 511-516, 2014, doi: 10.1016/j.procir.2014.03.049.

[3] N. H. B. Ambrizal, A. Farooqi, O. I. Alsultan, and N. Bin Yusoff, "Design and Development of CNC Robotic Machine Integrate-able with NdYag Laser Device," Procedia Eng., vol. 184, pp. 145-155, 2017, doi: 10.1016/j.proeng.2017.04.079.

[4] L. E. Chiang and J. Ramos, "CNC control of a laser cutting machine," Proceedings of 1994 IEEE International Symposium on Industrial Electronics (ISIE' 94), Santiago, Chile, 1994, pp. 236-241.

[5] A. Stepanov, M. Manninen, I. Pärnänen, M. Hirvimäki, and A. Salminen, "Laser Cutting of Leather: Tool for Industry or Designers?," Phys. Procedia, vol. 78, no. August, pp. 157-162, 2015, doi: 10.1016/j.phpro.2015.11.028.

[6] B. Jayachandraiah, O. V. Krishna, P. A. Khan, and R. A. Reddy, "Fabrication of Low Cost 3Axis Cnc Router," Int. J. Eng. Sci. Invent., vol. 3, no. 6, pp. 1-10, 2014, doi: http://www.ijesi.org/papers/Vol(3)6/Version -1/A036101010.pdf.

[7] G. M. Martinov, A. I. Obuhov, L. I. Martinova, and A. S. Grigoriev, "An Approach to Building a Specialized CNC System for Laser Engraving Machining," Procedia CIRP, vol. 41, pp. 9981003, 2016, doi: 10.1016/j.procir.2015.08.103.
[8] H. S. Rahman, I. F. Rahmad, and A. Saleh, "Perancangan Mesin Cnc (Computer Numericaly Control) Mini Plotter Berbasis Arduino of the Machine Cnc (Computer Numericaly Control) Mini Plotter Based," IT J., vol. 5, no. 2, pp. 152-161, 2017.

[9] S. Gordon and M. T. Hillery, "Development of a high-speed CNC cutting machine using linear motors," Journal of Materials Processing Technology, vol. 166, pp. 321-329, 2005.

[10] B. Weinberg and X. Yu, "Robotics in education: Low-cost platforms for teaching integrated systems," IEEE Robot. Autom. Mag., vol. 10, no. 2, pp. 4-6, 2003, doi: 10.1109/MRA.2003.1213610.

[11] Zheng, H. Y., et al. "Quality and cost comparisons between laser and waterjet cutting." Journal of Materials Processing Technology 62.4, 294-298, 1996.

[12] J. M. Kajal, R. N. Kranti, R. P. Pooja, and S. M. Vikas, "Automatic mini CNC machine for PCB drawing and drilling," Int. J. Recent Innov. Trends Comput. Commun., vol. 3, no. 12, pp. 2041-2042, 2016.

[13] L. S. Tegar and J. Utama, "Rancang Bangun Sistem Informasi Lahan Parkir Kendaraan Roda Empat di Unikom Berbasis Image Processing Designed Build Information System in Unikom Four-Wheeled Parking Lot based on Image Processing," Telekontran, vol. 4, no. 1, pp. 27-33, 2016.

[14] A. Syukri, J. D. Setiawan, and M. Ariyanto, "Rancang-bangun prototipe mesin CNC laser engraving dua sumbu menggunakan diode laser," J. Tek. Mesin Indones., vol. 13, no. 1, pp. 32$37,2018$.

[15] J. T. Elekterika, "Perancangan Pen Plotter Tiga Sumbu Berbasis Mikrokontroller Arduino," no. September, pp. 78-82, 2018.

[16] Sutisna, N. A and Fauzi, H, "Rancang Bangun Prototipe Mesin Gravir Laser Berbasis," J. Ind. Eng. Sci. J. Res. Appl. Ind. Syst., vol. 3, no. 2, pp. 90-104, 2018. 